\title{
Assessing Fitness Costs and Phenotypic Instability of Fentin Hydroxide and Tebuconazole Resistance in Venturia effusa
}

\author{
Jeffrey R. Standish, ${ }^{1, \dagger}$ Timothy B. Brenneman, ${ }^{1}$ Marin T. Brewer, ${ }^{2}$ and Katherine L. Stevenson ${ }^{1}$ \\ ${ }^{1}$ Department of Plant Pathology, Coastal Plain Experiment Station, The University of Georgia, Tifton, GA 31793 \\ ${ }^{2}$ Department of Plant Pathology, The University of Georgia, Athens, GA 30602
}

\begin{abstract}
Sensitivity monitoring of Venturia effusa, cause of pecan scab, has revealed insensitivity to fentin hydroxide and tebuconazole, but recent research indicates that the insensitivity to fentin hydroxide is not stable. A study was undertaken to determine if a fitness cost may be responsible for this instability. In this study, experiments were conducted to evaluate fitness components and phenotypic stability of insensitivity of $V$. effusa to fentin hydroxide and tebuconazole. Conidial production, conidial germination, microcolony growth, sensitivity to osmotic stress, and sensitivity to oxidative stress in the absence of fungicide were compared for isolates with differing sensitivities to both fungicides. Percent conidial germination

assessed on concentrations of $1.0,3.0$, and $10 \mu \mathrm{g} / \mathrm{ml}$ of both fungicides prior to and after five transfers on non-fungicide-amended medium. Tebuconazole insensitivity was stable after transfers, but fentin hydroxide insensitivity on 1.0 and $3.0 \mu \mathrm{g} / \mathrm{ml}$ decreased significantly after transfers, indicating instability. Here we provide evidence that in $V$. effusa tebuconazole insensitivity is stable and fentin hydroxide insensitivity is not. These results suggest that fentin-hydroxide-resistant $V$. effusa isolates have reduced conidial viability compared with sensitive isolates, which may allow the population to regain sensitivity in the absence of this frequently used fungicide.
\end{abstract} decreased linearly with increasing fentin hydroxide insensitivity, and microcolony growth on $1.0 \mathrm{mM} \mathrm{H}_{2} \mathrm{O}_{2}$ decreased linearly with increasing tebuconazole insensitivity. Stability of resistance was
Keywords: fungicide resistance, fitness penalty, organotin, triphenyltin hydroxide, demethylation inhibitor
In the southeastern United States, the successful management of pecan scab, caused by Venturia effusa (G. Winter) Rossman \& W.C. Allen (syn. Fusicladium effusum), is usually achieved with preventive fungicide applications made from April through August (Brock and Bertrand 2007a). Pecan producers are advised to apply fungicides using either a calendar-based schedule that results in 10 or more applications per season or a weather-based method that, in a dry season, requires fewer applications compared with the calendar-based method (Brenneman et al. 1998; Brock and Bertrand 2007b). Fungicides belonging to several different chemical groups are approved for use on pecan in the United States and include Fungicide Resistance Action Committee (FRAC) codes 1, 3, 11, 30, 33, M3, and U12, representing the methyl benzimidazole carbamates, demethylation inhibitors (DMIs), quinone outside inhibitors, organotin compounds, phosphonates, dithiocarbamates, and guanidines, respectively (Bock et al. 2017). The inherent risk of resistance developing in $V$. effusa to the active ingredients within each of these fungicide groups ranges from "low to medium" to "high" and is magnified by the inability to provide uniform coverage in larger pecan trees (Bertrand and Brenneman 2001; Bock et al. 2013; FRAC 2018). Moreover, V. effusa survives as stromata within the canopy of pecan trees from season to season, which, when combined with the potential for sexual recombination, leads to a high risk for resistance to develop in this pathogen (Demaree 1924; FRAC 2013; Young et al. 2018).

The results of a recent grower-funded sensitivity monitoring program revealed that the scab pathogen is gradually becoming less sensitive to several previously effective fungicides, specifically the

${ }^{\dagger}$ Corresponding author: J. R. Standish; jstandish@uga.edu

Funding: This research was supported by funds provided by the Georgia Commodity Commission for Pecans.

The author(s) declare no conflict of interest.

Accepted for publication 2 April 2019.

(C) 2019 The American Phytopathological Society organotin fungicide fentin hydroxide and the DMIs propiconazole and tebuconazole, and that the levels of insensitivity were consistent with fungicide use patterns across southwestern Georgia (Seyran et al. 2010; Stevenson et al. 2015). Insensitivity to both fentin hydroxide and the DMIs has historically followed a quantitative development pattern in which efficacy is slowly lost over time (Stevenson et al. 2015). Fitness, or the relative ability of an organism to survive and reproduce successfully, thereby contributing its genes to the next generation, plays a major role in the evolution and maintenance of fungicide resistance (Cox et al. 2007; Ishii 2015; Pringle and Taylor 2002). The cost of fungicide resistance may be reflected in the ability of the fungus to complete its life cycle and may specifically affect conidial production and dispersal, infection efficiency, mycelial growth, overwintering capabilities, and other life cycle components, and it may affect the ability to compete with fungicide-sensitive isolates in a field environment (Mikaberidze and McDonald 2015). Whether or not resistant isolates show a reduction in fitness appears to be dependent on the pathogen, the mode of action of the fungicide, and the mechanism of resistance (Hollomon 2015). If resistant isolates are less fit than sensitive isolates, the frequency of resistant isolates in the population will decrease in the absence of the fungicide, and resistance will not be stable (Mikaberidze and McDonald 2015). Over time, and dependent on the relative fitness cost associated with fungicide resistance, this could result in a mostly sensitive population and the re-establishment of fungicide efficacy (Ishii 2015). Whether isolates of $V$. effusa insensitive to fentin hydroxide or the DMI fungicides are as fit as their sensitive counterparts in the absence of the fungicides remains to be determined.

Pecan producers throughout the southeastern United States rely on fentin hydroxide, the only organotin labeled on pecan, and several DMIs, including propiconazole, fenbuconazole, tebuconazole, and others, for effective scab management. Thus, the objectives of this study were to (i) evaluate fitness components of isolates of $V$. effusa with differing levels of sensitivity to fentin hydroxide or tebuconazole, and (ii) investigate the stability of insensitivity to fentin hydroxide or tebuconazole over several successive hyphal transfers.

\section{Materials and Methods}

Fungal isolates and fungicide sensitivity testing. A total of 20 monoconidial isolates of $V$. effusa collected from Georgia pecan 
orchards were investigated in this study (Table 1). The isolates were grown on potato dextrose agar amended with tetracycline $(50 \mathrm{mg} /$ liter), streptomycin sulfate $(50 \mathrm{mg} / \mathrm{liter})$, and chloramphenicol $(50 \mathrm{mg} / \mathrm{liter})(\mathrm{PDA}+)$ in Petri dishes $(15 \times 100 \mathrm{~mm}$ diameter $)$. After 4 to 6 weeks, five 6-mm-diameter mycelial plugs from each respective $V$. effusa colony were removed and placed into a microcentrifuge tube containing $1 \mathrm{ml}$ of sterile potato dextrose broth (PDB) and three sterile 3-mm glass beads. Fungal material was macerated using a bead beating apparatus (Mini-Bead Beater, Biospec, Bartlesville, $\mathrm{OK}$ ) for $1 \mathrm{~min}$ before being transferred to a tube containing $5 \mathrm{ml}$ of PDB and mixed using a vortex mixer. This fungal slurry was pipetted in aliquots of $0.6 \mathrm{ml}$ and spread across Petri dishes (15 $\mathrm{mm}$ deep $\times 60 \mathrm{~mm}$ diameter) containing oatmeal agar $(30 \mathrm{~g}$ of ground oats [Quaker Oats Company, Chicago, IL] and $20 \mathrm{~g}$ of agar per liter of water) amended with the previously mentioned antibiotics (OA+) (Turechek and Stevenson 1998). Dishes were incubated under a 14-h day/night cycle with fluorescent light sources at $25^{\circ} \mathrm{C}$ for 14 days, after which the cultures were flooded with $4 \mathrm{ml}$ of sterile deionized water containing $0.1 \%$ Tween 20 , and conidia were liberated by agitation using a sterile glass rod (Turechek and Stevenson 1998). The resulting conidial suspension was centrifuged at 6,500 rpm for $6 \mathrm{~min}$, the supernatant decanted, and the conidial pellet resuspended in $2 \mathrm{ml}$ of sterile deionized water containing $0.1 \%$ Tween 20 (Cancro 2000). This solution was filtered through two layers of sterile cheesecloth and the concentration of conidia adjusted to $1 \times 10^{5}$ conidia/ml using a hemocytometer (Turechek and Stevenson 1998). Sensitivity of individual isolates to discriminatory concentrations of fentin hydroxide and tebuconazole was determined by modifying a bulk-spore assay that was originally designed for leaf samples and described by Seyran et al. (2010). Technical-grade fentin hydroxide $(98.7 \%$ active ingredient; Chem Service, West Chester, PA) and tebuconazole (97.5\% active ingredient; Bayer CropScience, Research Triangle Park, NC) were each dissolved in acetone to reach

Table 1. Year of collection and sensitivity to fentin hydroxide and tebuconazole of Venturia effusa isolates used in this study

\begin{tabular}{|c|c|c|c|c|c|}
\hline \multirow[b]{3}{*}{ Isolate } & \multirow[b]{3}{*}{ Year } & \multirow{2}{*}{\multicolumn{2}{|c|}{ Fungicide sensitivity }} & \multicolumn{2}{|c|}{ Phenotypic stabilitya } \\
\hline & & & & \multirow{2}{*}{$\begin{array}{c}\text { Fentin } \\
\text { hydroxide }\end{array}$} & \multirow[b]{2}{*}{ Tebuconazole } \\
\hline & & $\mathbf{R G e}^{\mathbf{b}}$ & $\mathbf{R G r}^{\mathbf{c}}$ & & \\
\hline TC6 & 1997 & $5.8(0.3)$ & $0.0(-)$ & $x$ & $x$ \\
\hline TC17 & 1997 & $2.1(1.0)$ & $0.0(-)$ & & \\
\hline P16AT1 & 2016 & $4.4(1.2)$ & - & $x$ & \\
\hline P16AT2 & 2016 & $0.0(-)$ & $25.4(3.0)$ & $x$ & \\
\hline P16AT7 & 2016 & $0.0(-)$ & $81.9(4.4)$ & & \\
\hline P16FH1 & 2016 & $7.4(5.2)$ & $52.3(13.7)$ & & \\
\hline $\mathrm{P} 16 \mathrm{FH} 2$ & 2016 & $16.4(3.3)$ & $57.2(1.8)$ & $x$ & $x$ \\
\hline $\mathrm{P} 16 \mathrm{FH} 3$ & 2016 & $0.0(-)$ & - & & \\
\hline P16FHT1 & 2016 & $3.4(0.4)$ & $47.7(15.4)$ & $x$ & $x$ \\
\hline P16FHT2 & 2016 & $10.5(3.0)$ & - & & \\
\hline P16NTC1 & 2016 & $4.1(1.5)$ & $54.8(0.2)$ & $x$ & $x$ \\
\hline P16NTC2 & 2016 & $8.4(1.3)$ & - & & \\
\hline P16T1 & 2016 & $0.0(-)$ & $10.8(7.4)$ & & $x$ \\
\hline $\mathrm{P} 16 \mathrm{~T} 2$ & 2016 & $0.0(-)$ & $22.1(2.0)$ & $x$ & \\
\hline P16T3 & 2016 & $13.3(2.9)$ & $43.0(8.0)$ & & \\
\hline P16T4 & 2016 & - & $51.7(3.0)$ & & \\
\hline P16T5 & 2016 & $0.0(-)$ & $13.5(7.4)$ & $x$ & $x$ \\
\hline P16T6 & 2016 & $0.0(-)$ & $71.3(1.0)$ & $x$ & $x$ \\
\hline P171G & 2017 & - & $16.4(0.7)$ & & \\
\hline P171T & 2017 & - & $46.3(5.7)$ & & $x$ \\
\hline
\end{tabular}

$\bar{a}$ Phenotypic stability of fentin hydroxide and tebuconazole insensitivity was assessed on subsets of $V$. effusa isolates indicated by " $X$ ".

${ }^{\mathrm{b}} \mathrm{RGe}=$ relative germination calculated as the proportion of germinated conidia on medium amended with $10.0 \mu \mathrm{g} / \mathrm{ml}$ of fentin hydroxide divided by the proportion of those germinated on nonamended medium and multiplied by 100. Values are percentages with standard errors in parentheses.

${ }^{\mathrm{c}} \mathrm{RGr}=$ relative growth, calculated by taking the corrected mean diameter of 10 microcolonies on media amended with $3.0 \mu \mathrm{g} / \mathrm{ml}$ of tebuconazole and multiplied by 100 . Values are percentages with standard errors in parentheses. concentrations of 10,000 and $3,000 \mu \mathrm{g} / \mathrm{ml}$, respectively. The final concentration of $10 \mu \mathrm{g} / \mathrm{ml}$ of fentin hydroxide in medium was obtained by adding $1 \mathrm{ml}$ of the fungicide solution to 1 liter of autoclaved $2 \%$ water agar (WA; $20 \mathrm{~g}$ of agar per liter of water) that had cooled in a water bath to $50^{\circ} \mathrm{C}$. Alternatively, owing to the difference in time needed for the testing procedures, additional nutrients were required in media when assessing microcolony growth. Thus, $1 \mathrm{ml}$ of the tebuconazole stock solution was added to 1 liter of autoclaved and cooled quarter-strength PDA (qPDA; $9.75 \mathrm{~g}$ of PDA and $11.25 \mathrm{~g}$ of agar per liter of water) instead of WA, to reach a final concentration of 3 $\mu \mathrm{g} / \mathrm{ml}$. These concentrations were selected based on sensitivity monitoring to the two fungicides in previous studies (Seyran et al. 2010; Standish et al. 2018; Stevenson et al. 2015). Non-fungicideamended WA and qPDA control media were prepared by adding $1 \mathrm{ml}$ of acetone to 1 liter of WA or qPDA that had been autoclaved and cooled.

Conidial suspensions for each isolate were transferred in aliquots of $50 \mu \mathrm{l}$ and spread across three replicate dishes of fentinhydroxide-amended and nonamended WA (17 of 20 total isolates), as well as three replicate dishes of tebuconazole-amended and nonamended qPDA (16 of 20 total isolates). The conidia were incubated in the dark at room temperature $\left(23\right.$ to $\left.25^{\circ} \mathrm{C}\right)$ for $48 \mathrm{~h}$ for fentin hydroxide or $72 \mathrm{~h}$ for tebuconazole sensitivity testing. Fentin hydroxide is a protectant fungicide with activity against conidial germination. Thus, to assess sensitivity to this fungicide, conidial germination was determined by arbitrarily selecting 50 conidia per replicate dish and counting the number that had germ tubes of a length of at least four times the diameter of the conidium using a compound microscope at a magnification of $100 \times$. Conidial germination was then quantified as percent relative germination $(\mathrm{RGe})$, the proportion of germinated conidia on the fentinhydroxide-amended medium divided by the proportion of germinated conidia on the nonamended medium, multiplied by 100 (Seyran et al. 2010). Microcolony growth was used to test sensitivity to tebuconazole, because DMI fungicides do not have activity against conidial germination (Scheinpflug and Kuck 1987). Ten individual microcolonies were selected per replicate plate and measured using a compound microscope (100x) as described by Seyran et al. (2010). All microcolony growth measurements were corrected for the average length of a germinated conidium and germ tube by subtracting $15 \mu \mathrm{m}$ from all microcolony measurements (Standish et al. 2018). Microcolony growth was expressed as relative growth (RGr), calculated as the corrected mean diameter of 10 colonies on tebuconazole-amended medium divided by the corrected mean diameter of 10 colonies on nonamended medium and multiplied by 100 . The assays to determine sensitivity to both fentin hydroxide and tebuconazole were conducted twice.

Fitness assessments. For each isolate, the following fitness components were evaluated: conidial production, germination ability, microcolony growth, sensitivity to osmotic stress, and sensitivity to oxidative stress. Experiments for each component were conducted three times, each with three replicates, and the isolates used were maintained on PDA+ throughout the course of the study. To assess conidial production in vitro, a fungal slurry, made for each isolate as described previously, was pipetted in aliquots of $0.6 \mathrm{ml}$ and spread across Petri dishes ( $15 \mathrm{~mm}$ deep $\times 60 \mathrm{~mm}$ diameter $)$ containing $\mathrm{OA}+$. Cultures were incubated, and conidia were collected using the protocols described above. The concentration of conidia was estimated using a hemocytometer and was expressed as the number of conidia produced per $\mathrm{mm}^{2}$ of colony area. Conidial germination and microcolony growth were measured by collecting conidia from actively sporulating cultures of each isolate on $\mathrm{OA}+$ as described above. The concentration of conidia was determined and adjusted to a final concentration of $1 \times 10^{4}$ conidia/ml using a hemocytometer (Turechek and Stevenson 1998). Conidial suspensions for each isolate were transferred onto three dishes of WA and three dishes of qPDA in aliquots of $50 \mu l$ that were then spread across the respective media. The plates were placed in the dark and kept at room temperature $\left(23\right.$ to $\left.25^{\circ} \mathrm{C}\right)$. Conidial germination was assessed after $48 \mathrm{~h}$ as described above, and microcolony 
growth was measured after $72 \mathrm{~h}$, also as described above with the exception that the measurements were corrected by subtracting $2 \mu \mathrm{m}$ to represent the average length of a conidium. Sensitivity to osmotic stress was determined by comparing microcolony growth of isolates on PDA amended with 2,4 , or $6 \% \mathrm{NaCl}(20$, 40 , or $60 \mathrm{~g}$ of $\mathrm{NaCl}$ per liter of PDA, respectively) as described by Chen et al. (2016). Similarly, sensitivity to oxidative stress was determined by comparing microcolony growth of isolates on PDA supplemented with $0.1,1.0$, or $10 \mathrm{mM}$ hydrogen peroxide $\left(\mathrm{H}_{2} \mathrm{O}_{2} ; 3 \%\right.$ stabilized solution). Microcolony diameters were measured as previously described and were corrected by subtracting the average length of a conidium $(2 \mu \mathrm{m})$.

Phenotypic stability of insensitivity to fentin hydroxide and tebuconazole. To test if isolate sensitivity or insensitivity was stable, RGe or RGr was determined for a subset of isolates on fentin hydroxide (nine isolates) or tebuconazole (eight isolates), respectively, on WA and qPDA before and after five aseptic transfers (Table 1). Conidia were collected from actively sporulating cultures of each isolate on $\mathrm{OA}+$ as described above, and a hyphal tip from the edge of the culture was transferred onto qPDA amended with the previously mentioned antibiotics. These cultures were incubated at $25^{\circ} \mathrm{C}$ in the dark for 14 days before a new hyphal-tip transfer was made. In total, five transfers were made before conidia were produced and collected again, as previously described. For the initial and final cultures of each isolate, conidial germination and microcolony growth were assessed on medium amended with three concentrations of fentin hydroxide (1.0, 3.0 , and $10.0 \mu \mathrm{g} / \mathrm{ml}$ ) or tebuconazole $(1.0,3.0$, and $10.0 \mu \mathrm{g} / \mathrm{ml})$. These fungicide concentrations were included to observe a dose response and were selected based on the results of previous sensitivity monitoring experiments (Seyran et al. 2010; Standish et al. 2018; Stevenson et al. 2015). Fungicide-amended and nonamended media were prepared as previously described with the exception that stock solutions of 1,000 and $3,000 \mu \mathrm{g} / \mathrm{ml}$ of fentin hydroxide in acetone (final concentrations of 1.0 and $3.0 \mu \mathrm{g} / \mathrm{ml}$ in medium) and 1,000 and $10,000 \mu \mathrm{g} / \mathrm{ml}$ of tebuconazole in acetone (final concentrations of 1.0 and $10.0 \mu \mathrm{g} / \mathrm{ml}$ in medium) were also included. Conidial germination was expressed as $\mathrm{RGe}$, and microcolony growth was expressed as RGr, as described above. Three replicate plates were prepared for each isolate, and the experiment was conducted twice.

Data analysis. Statistical analyses of fitness components and phenotypic stability were performed separately for fentin hydroxide and tebuconazole sensitivity datasets. A linear mixed-model regression analysis was conducted using PROC MIXED in SAS (version 9.4, SAS Institute, Cary, NC) to determine the effects of sensitivity on the previously described fitness parameters. In these analyses, sensitivity values for fentin hydroxide (RGe) or tebuconazole ( $\mathrm{RGr}$ ) were continuous variables and treated as covariates. Experiment was included as a class variable and was analyzed to determine whether the relationship between RGe or RGr values and each of the fitness parameters was similar for all experiments. Residuals for each fitness component and stability test were assessed for normality. For phenotypic stability, a nonparametric paired $t$ test (Wilcoxon signed-rank test) was performed using PROC UNIVARIATE in SAS to determine significant differences between experimental repeats. The same test was used to compare RGe or RGr values on the three concentrations of each fungicide before and after five transfers on nonamended media.

\section{Results}

Fungicide sensitivity. Twenty isolates were chosen to be included in this study; however, data were obtained from only 17 and 16 of those included for fitness testing of fentin hydroxide and tebuconazole insensitivities, respectively. The mean fentin hydroxide $\mathrm{RGe}$ values on $10 \mu \mathrm{g} / \mathrm{ml}$ ranged from 0.0 to $16.4 \%$, whereas the mean tebuconazole sensitivity values on $3 \mu \mathrm{g} / \mathrm{ml}$ ranged from 0.0 to $81.9 \%$ (Table 1).

Fitness testing. For fentin hydroxide sensitivity, the distribution of residuals for conidial production and microcolony growth on medium amended with $1.0 \mathrm{mM} \mathrm{H}_{2} \mathrm{O}_{2}$ differed significantly from normality. Similarly, for tebuconazole sensitivity, the residuals for conidial production and microcolony growth on both $2 \%$ $\mathrm{NaCl}$-amended and $1.0 \mathrm{mM} \mathrm{H}_{2} \mathrm{O}_{2}$-amended media were nonnormally distributed. Variables with nonnormally distributed residuals were natural $\log (\ln )$ transformed prior to analysis. For all isolates, poor conidial germination was observed on $4 \% \mathrm{NaCl}$ (between 5.5 and $35.0 \%$ ), $6 \% \mathrm{NaCl}$ (between 4.7 and $20.0 \%$ ), and $10 \mathrm{mM} \mathrm{H}_{2} \mathrm{O}_{2}$ (between 4.4 and 24.4\%); thus, microcolony growth data were not collected, and these components were omitted from further analysis. The experiment effect was not significant for any of the tested fitness parameters, indicating that the linear relationships between those parameters and fentin hydroxide $\mathrm{RGe}$ values were similar across the three experiments (i.e., intercepts and slopes of different experiments did not differ significantly). The effects of fentin hydroxide RGe values on combined results for sporulation (as conidial production per $\mathrm{mm}^{2}$ ) and microcolony growth on qPDA, $2 \%$ $\mathrm{NaCl}, 0.1 \mathrm{mM} \mathrm{H} \mathrm{H}_{2} \mathrm{O}_{2}$, and $1.0 \mathrm{mM} \mathrm{H}_{2} \mathrm{O}_{2}$ were not significant (Table 2). The effects of fentin hydroxide $\mathrm{RGe}$ values on percent germination were examined across three experiments, but in the first experiment, the two least sensitive isolates (P16FH2 and P16T3; Table 1) failed to produce enough conidia for germination testing, and the results of experiment 1 were not included in the final analysis. However, the combined results of experiments 2 and 3 showed a significant $(P=0.0014)$ and negative linear trend; percent germination decreased with increasing RGe values (Table 2; Fig. 1). Similarly, the effect of experiment was not significant for any of the tested fitness parameters and tebuconazole RGr values. For

Table 2. Significance levels ( $P$ values) from linear mixed-model regression analyses to determine overall effects of initial sensitivity to fentin hydroxide and tebuconazole on fitness components in isolates of Venturia effusa ${ }^{\text {a }}$

\begin{tabular}{|c|c|c|c|c|c|c|}
\hline \multirow[b]{2}{*}{ Fixed effects ${ }^{c}$} & \multirow[b]{2}{*}{ Sporulation $\left(\mathrm{mm}^{2}\right)$} & \multirow[b]{2}{*}{ Germination (\%) } & \multirow[b]{2}{*}{ Microcolony growth $(\mu \mathrm{m})$} & \multicolumn{3}{|c|}{ Osmotic and oxidative stress ${ }^{b}$} \\
\hline & & & & $2 \% \mathrm{NaCl}$ & $0.1 \mathrm{mM} \mathrm{H}_{2} \mathrm{O}_{2}$ & $1.0 \mathrm{mM} \mathrm{H} \mathrm{H}_{2} \mathrm{O}_{2}$ \\
\hline \multicolumn{7}{|c|}{ Fentin hydroxide } \\
\hline Exp & 0.7573 & 0.3476 & 0.8698 & 0.5672 & 0.9702 & 0.7210 \\
\hline $\mathrm{RGe}$ & 0.2664 & 0.0014 & 0.3488 & 0.6121 & 0.2036 & 0.3748 \\
\hline $\mathrm{RGe} \times \operatorname{Exp}$ & 0.3326 & 0.9983 & 0.5083 & 0.1625 & 0.6110 & 0.7477 \\
\hline \multicolumn{7}{|l|}{ Tebuconazole } \\
\hline Exp & 0.9085 & 0.5718 & 0.3121 & 0.5624 & 0.4980 & 0.2726 \\
\hline RGr & 0.1324 & 0.3818 & 0.5767 & 0.7595 & 0.8847 & 0.0023 \\
\hline $\mathrm{RGr} \times \operatorname{Exp}$ & 0.8767 & 0.8205 & 0.2029 & 0.6089 & 0.5034 & 0.6977 \\
\hline
\end{tabular}

a Significant effects of experiment, initial sensitivity (RGe or RGr), and the combinations are boldfaced $(P \leq 0.05)$. The $P$ values for sporulation and $1.0 \mathrm{mM}$ $\mathrm{H}_{2} \mathrm{O}_{2}$ for both fentin hydroxide and tebuconazole and the values of $2 \% \mathrm{NaCl}$ for tebuconazole are based on an analysis of ln-transformed data.

b Osmotic and oxidative stress assessed as microcolony growth $(\mu \mathrm{m})$ on media amended with $2 \% \mathrm{NaCl}$ or 0.1 and 1.0 mM $\mathrm{H}_{2} \mathrm{O}_{2}$, respectively; growth on 4 and $6 \% \mathrm{NaCl}$ and $10 \mathrm{mM} \mathrm{H}_{2} \mathrm{O}_{2}$ is not shown.

${ }^{\mathrm{c}}$ Abbreviations: Exp = experiment; RGe = relative germination on fentin-hydroxide-amended medium $(10 \mu \mathrm{g} / \mathrm{ml})$; and RGr $=$ relative growth on tebuconazoleamended medium $(3 \mu \mathrm{g} / \mathrm{ml})$. 
combined results of tebuconazole insensitivity, the effects of $\mathrm{RGr}$ on sporulation, percent germination, or microcolony growth on qPDA, $2 \% \mathrm{NaCl}$, and $0.1 \mathrm{mM} \mathrm{H}_{2} \mathrm{O}_{2}$ were not significant. However, the effects of tebuconazole $\mathrm{RGr}$ values on microcolony growth on $1.0 \mathrm{mM} \mathrm{H}_{2} \mathrm{O}_{2}$ were significant $(P=0.0023)$ (Table 2). The combined experiments revealed that $\ln$-transformed microcolony growth on $1.0 \mathrm{mM} \mathrm{H} \mathrm{H}_{2}$ decreased linearly with increasing $\mathrm{RGr}$ on tebuconazole-amended medium (Fig. 2).

Phenotypic stability of insensitivity to fentin hydroxide and tebuconazole. Experimental repeats for fentin hydroxide $\mathrm{RGe}$ and tebuconazole RGr values on each of the three concentrations before and after transfers did not differ significantly and were combined across experiments. For fentin hydroxide, the mean $\mathrm{RGe}$ values on $1.0 \mu \mathrm{g} / \mathrm{ml}$ before and after transfer were 92.5 and $72.8 \%$, respectively, and represented a significant decrease in RGe (Table 3). Similarly, the mean RGe values before and after transfer on $3.0 \mu \mathrm{g} / \mathrm{ml}$ were 72.2 and $35.5 \%$, respectively, and the decrease was significant (Table 3). The mean RGe before and after transfers on $10 \mu \mathrm{g} / \mathrm{ml}$ did not differ significantly but did decrease from 7.5 to $3.2 \%$. Mean tebuconazole RGr values on 1.0, 3.0, and $10.0 \mu \mathrm{g} / \mathrm{ml}$ before and after transfers were 56.2 and $55.3 \%, 31.0$ and $19.8 \%$, and 2.8 and $2.3 \%$, respectively, and did not differ significantly before or after transfers on any of the three concentrations tested (Table 3).

\section{Discussion}

Understanding the fitness differences of $V$. effusa isolates resistant and sensitive to fentin hydroxide and tebuconazole could aid in the development of additional resistance management strategies to combat fungicide resistance in V. effusa (Brent and Hollomon 2007). Thus, the focus of this study was to assess variation in fitness components of isolates of $V$. effusa with varying levels of insensitivity to fentin hydroxide or tebuconazole and to identify if these insensitivities were stable after several successive vegetative transfers. Our results provide evidence of fitness penalties associated with both fentin hydroxide and tebuconazole insensitivity. Conidia produced by fentin-hydroxide-insensitive isolates were less viable than those produced by more sensitive isolates, and insensitivity was not stable; insensitivity decreased significantly after five consecutive transfers on nonamended media. Additionally, isolates with greater insensitivity to tebuconazole grew less than sensitive isolates on media amended with $1.0 \mathrm{mM} \mathrm{H} \mathrm{H}_{2} \mathrm{O}_{2}$. If the oxidative burst associated with pathogen recognition in other plants occurs in pecan (Torres et al. 2006), these isolates would be expected to grow less within the plant after infection. However, tebuconazole RGr values calculated before transfers did not differ significantly from those determined after transfers, indicating that tebuconazole insensitivity is phenotypically stable.

In the United States, fentin hydroxide is only labeled for use on pecan, potato, and sugar beet (as Super Tin 4L [United Phosphorus, King of Prussia, PA] and Agri Tin [Nufarm Americas, Burr Ridge, IL]). Within this limited number of crops, practical resistance to fentin hydroxide has become an issue for only one other pathogen. In the case of the sugar beet leaf spot pathogen, Cercospora beticola, isolates tolerant to the organotin fungicides fentin acetate and fentin chloride were first described in 1976 (Giannopolitis 1978) and subsequently caused less severe leaf spot epidemics on untreated sugar beets when compared with more sensitive isolates (Giannopolitis and Chrysayi-Tokousbalides 1980). Isolates of $C$. beticola insensitive to fentin hydroxide were first reported in the United States in 1994, but interestingly, decreased in frequency when annual applications of fentin hydroxide declined between 1998 and 2008 (Bugbee 1996; Secor et al. 2010). A similar phenomenon, although on a shorter timescale, was observed for $V$. effusa in which RGe values, on $30 \mu \mathrm{g} / \mathrm{ml}$ of fentin hydroxide, of isolates collected in September 2016 were over 10 times greater than those isolates collected from the same trees in June 2017 (Standish et al. 2018). The effect of fentin hydroxide insensitivity on the ability of these isolates to infect pecan is currently unknown. Attempts to inoculate leaflets with several isolates were unsuccessful owing to the variable length of leaflet susceptibility coupled with the time required to produce the required inoculum. Nevertheless, our results provide evidence that more insensitive isolates produce less viable conidia, which, in the absence of fentin hydroxide, could lead to a reduction in the frequency of insensitive isolates in the $V$. effusa population. The pathogen overwinters as stromata within lesions on the leaves, shoots, and shucks of pecan trees, and conidia

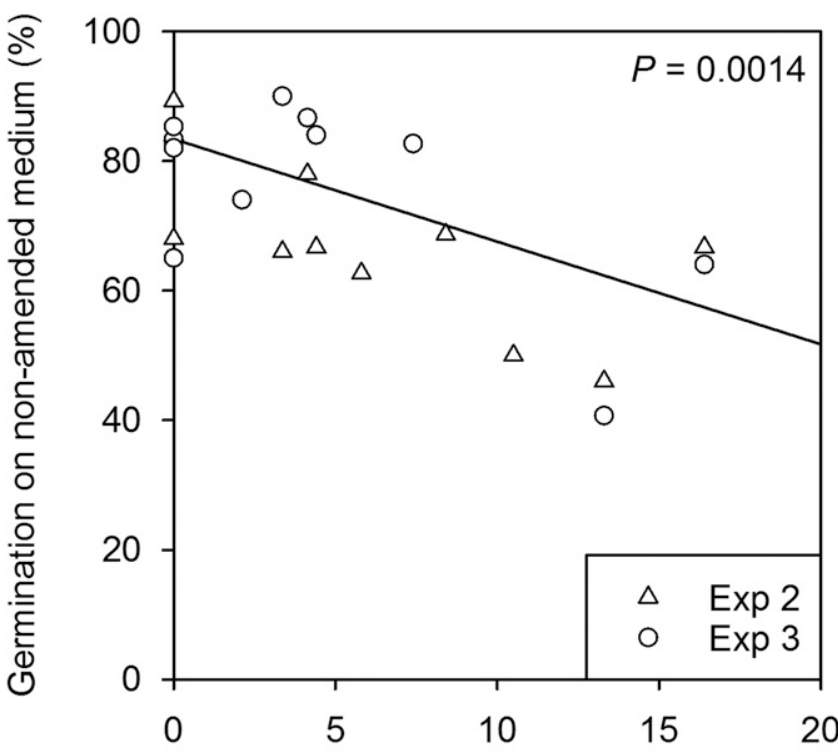

Germination on amended medium (\%)

Fig. 1. Relationship between sensitivity of nine Venturia effusa isolates to fentin hydroxide, measured as percent relative conidial germination on water agar amended with $10 \mu \mathrm{g} / \mathrm{ml}$ fentin hydroxide $(x)$, and percent conidial germination on nonamended water agar $(y)$. Results of two experiments are shown. Data points are the means of three replications of each isolate. A common relationship is shown and can be described by the linear equation, given as $y=83.4-1.58 x$.
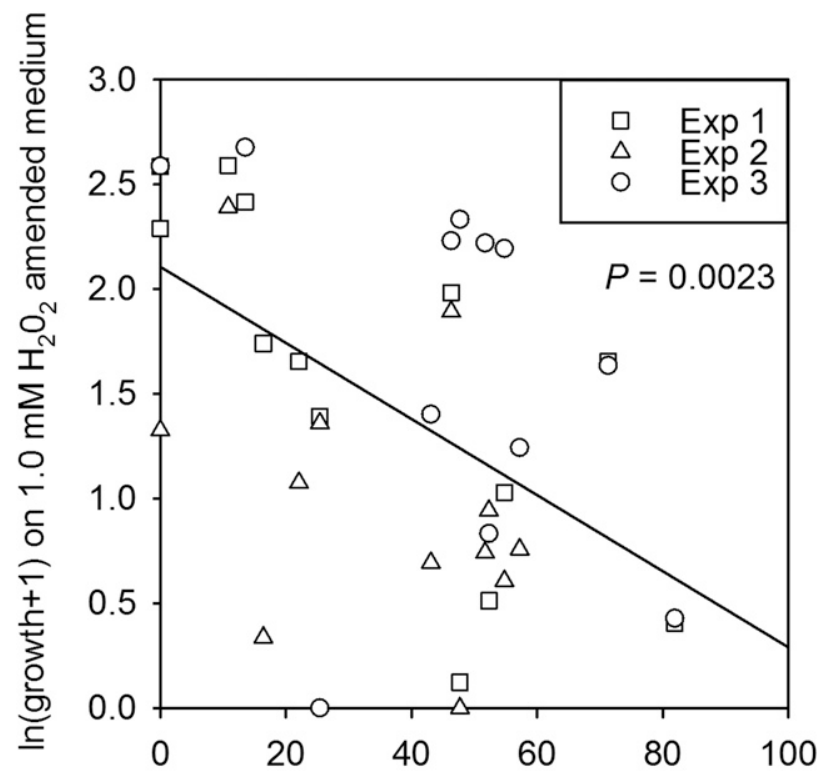

Relative growth on $3.0 \mu \mathrm{g} / \mathrm{ml}$ tebuconazole (\%)

Fig. 2. Relationship between sensitivity of eight Venturia effusa isolates to tebuconazole $(x)$ and In-transformed microcolony growth $(\mu \mathrm{m})$ on medium amended with $1.0 \mathrm{mM} \mathrm{H}_{2} \mathrm{O}_{2}(\mathrm{y})$. Results of three experiments are shown. Data points are the means of three replications of each isolate. A common relationship is shown and can be described by the linear equation, given as $y=2.11-0.018 x$. 
arise from those stromata in the spring when new leaves are unfolding (Demaree 1924). If stromata were produced by fentin-hydroxideinsensitive isolates, then it is possible that conidia produced from those stromata could be less viable and result in a lower frequency of insensitive isolates in the population at the beginning of a given year. Whether or not this occurs in commercial orchards is not known, and future research is needed to better understand the epidemiological consequences of fitness penalties associated with fentin hydroxide insensitivity in isolates of $V$. effusa. After five consecutive transfers on a fungicide-free medium, fentin hydroxide RGe values decreased significantly when tested on 1.0 and $3.0 \mu \mathrm{g} / \mathrm{ml}$, respectively. This provides evidence that corroborates the field-based observations of Secor et al. (2010) for C. beticola and Standish et al. (2018) for $V$. effusa in which the overall frequency of resistant isolates, or RGe values, decreased substantially in the absence of fentin hydroxide applications. Taken together, these results indicate that fentin hydroxide insensitivity may not be stable, which suggests that the mechanism of resistance is not a target site mutation but a temporary adaptation of the pathogen to the fungicide. The mechanism of resistance by which pathogens overcome organotin activity is not well understood and merits further examination in $V$. effusa.

The DMIs are a large group of broad-spectrum fungicides that exhibit systemic properties, making them valuable for the control of a wide range of plant pathogens (Ziogas and Malandrakis 2015). Resistance to these fungicides may arise from target-site alterations, target-site overexpression, or the activity of membranebound drug transporters (Ma et al. 2006; Price et al. 2015; Schnabel and Jones 2001; Ziogas and Malandrakis 2015) and typically follows a quantitative development pattern. Practical resistance to the DMIs has been observed in populations of certain pathogens, including V. effusa (Reynolds et al. 1997; Standish et al. 2018; Ziogas and Malandrakis 2015). Fitness costs have been associated with DMI insensitivity for some pathogens but not for others. When the fitness of flutriafol-resistant and -sensitive isolates of $C$. beticola was compared, resistant isolates were less virulent and produced fewer conidia than their sensitive counterparts (Karaoglanidis et al. 2001). Furthermore, the frequency of flutriafol-resistant isolates decreased significantly in competition with sensitive isolates (Karaoglanidis et al. 2001). The results of a follow-up study provided evidence that flutriafol sensitivity was stable after consecutive transfers on nonamended media but that an increase in sensitivity occurred in isolates exposed to cold conditions (Karaoglanidis and Thanassoulopoulos 2002). A similar phenomenon was observed in isolates of Venturia inaequalis; flusilazole insensitivity was stable after 10 months of subculturing, but sensitivity increased considerably for the same isolates after 7 months of storage at $2^{\circ} \mathrm{C}$ (Köller et al. 1991). Interestingly, instability of propiconazole resistance was observed in isolates of Monilinia fructicola; percent inhibition increased significantly following both eight consecutive transfers in vitro and months stored at $5^{\circ} \mathrm{C}$ (tested at 0,8 , and 34 months, respectively) (Cox et al. 2007). For resistant isolates of $M$. fructicola, conidial production, conidial germination, and growth rate were lower, but this was not a consistent observation at each of the five evaluations that followed specific consecutive transfers (transfers 2, 5, 8, 11, and 14) (Cox et al. 2007).

Fitness of an isolate may vary depending on the particular mechanisms of resistance and could be based on the functional constraints of a target-site mutation versus the resource allocation costs associated with target-site overexpression or drug transporter activity (Hawkins and Fraaije 2018). In the current study, tebuconazole insensitivity was phenotypically stable after five consecutive transfers, and insensitivity was not compared under cold storage conditions. However, microcolony growth on $1.0 \mathrm{mM} \mathrm{H}_{2} \mathrm{O}_{2}$ was negatively correlated with tebuconazole insensitivity. To our knowledge, this is the first report of an observed association between hypersensitivity to oxidative stress and DMI resistance; however, evidence of hypersensitivity to oxidative stress has been observed in Alternaria alternata isolates resistant to succinate dehydrogenase inhibitors that were collected from pistachio and peach (Avenot et al. 2009; Fan et al. 2015). The concentration of hydrogen peroxide in plant tissues is in the micromole to low millimole range (Cheeseman 2006; Møller et al. 2007), which corresponds with the concentrations used in this study. As previously mentioned, attempts to inoculate pecan leaflets with isolates of $V$. effusa were unsuccessful; hence, the cost of oxidative stress associated with tebuconazole insensitivity could not be directly tested on the host plant. Nevertheless, this study provides evidence that tebuconazole-insensitive isolates are more likely to be sensitive to an oxidative burst, like that which often follows successful pathogen recognition in the plant, compared with sensitive isolates (Torres et al. 2006). Cross resistance is known to occur in V. effusa among the DMI fungicides fenbuconazole, propiconazole, and tebuconazole (Reynolds et al. 1997; Stevenson et al. 2015). Thus, the fitness of isolates insensitive to one or all of those DMI fungicides is likely to be similar; however, cross-resistance among DMIs is incomplete and has not been observed with difenoconazole (Stevenson et al. 2015). Fitness differences could occur based on the DMI fungicide for which insensitivity occurs, but practical resistance of $V$. effusa to difenoconazole has not been reported to date (Stevenson et al. 2015). The specific mechanism or mechanisms of resistance to the DMIs is unknown for isolates of $V$. effusa, and its identification should be a priority moving forward.

In this study, we have provided evidence that in the absence of fentin hydroxide, fentin-hydroxide-insensitive isolates of $V$. effusa produce less viable conidia than do sensitive isolates. Likewise, tebuconazole-insensitive isolates were more sensitive to oxidative stress in the absence of tebuconazole than were isolates sensitive to tebuconazole. Fentin hydroxide insensitivity to concentrations of 1.0 and $3.0 \mu \mathrm{g} / \mathrm{ml}$ was not stable, whereas insensitivity to three concentrations of tebuconazole was stable after five mycelial transfers. Further research is required to investigate the epidemiological consequences of fitness penalties associated with resistance to these two fungicides. However, in addition to insensitive isolates showing reduced fitness compared with sensitive isolates, the evidence that fentin hydroxide resistance is not stable indicates that a resistant $V$. effusa population may shift toward sensitivity in the absence of selection with this frequently used fungicide, therefore providing a crucial building block for resistance management strategies.

Table 3. In vitro sensitivity of Venturia effusa isolates to fentin hydroxide and tebuconazole prior to and after five consecutive transfers on quarter-strength potato dextrose agar

\begin{tabular}{|c|c|c|c|c|c|c|}
\hline \multirow[b]{2}{*}{ Concentration } & \multicolumn{3}{|c|}{ Fentin hydroxide } & \multicolumn{3}{|c|}{ Tebuconazole ${ }^{b}$} \\
\hline & Before & After & $P$ value $^{c}$ & Before & After & $P$ value $^{c}$ \\
\hline $1.0 \mu \mathrm{g} / \mathrm{ml}$ & $92.5(1.8)$ & $72.8(4.3)$ & 0.0008 & $56.2(6.5)$ & $55.3(7.2)$ & 0.6685 \\
\hline $3.0 \mu \mathrm{g} / \mathrm{ml}$ & $72.2(5.6)$ & $35.5(4.6)$ & 0.0003 & $31.0(5.1)$ & $19.8(4.4)$ & 0.1439 \\
\hline $10.0 \mu \mathrm{g} / \mathrm{ml}$ & $7.5(2.1)$ & $3.2(1.0)$ & 0.1706 & $2.8(1.0)$ & $2.3(0.9)$ & 0.6848 \\
\hline
\end{tabular}

a Values are relative germination: the proportion of germinated conidia on medium amended with 1.0, 3.0, or $10.0 \mu \mathrm{g} / \mathrm{ml}$ of fentin hydroxide divided by the proportion of germinated conidia on the nonamended medium and multiplied by 100 . Values are the means of nine isolates with standard errors in parentheses taken before and after five hyphal-tip transfers on nonamended medium.

${ }^{\mathrm{b}}$ Values are relative growth: the corrected mean diameter of 10 microcolonies on medium amended with $1.0,3.0$, or $10.0 \mu \mathrm{g} / \mathrm{ml}$ of tebuconazole and multiplied by 100 . Values are the means of eight isolates with standard errors in parentheses taken before and after five hyphal tip transfers on nonamended media.

${ }^{c} P$ values based on the Wilcoxon signed-rank test; significant effects are boldfaced $(P \leq 0.05)$. 


\section{Acknowledgments}

We thank C. T. Griffin, M. K. Lee, and O. B. Prokosch for their technical assistance in the laboratory and J. C. Fountain for technical consultation.

\section{Literature Cited}

Avenot, H., Sellam, A., and Michailides, T. 2009. Characterization of mutation in the membrane-anchored subunits AaSDHC and AaSDHD of succinate dehydrogenase from Alternaria alternata isolates conferring field resistance to the fungicide boscalid. Plant Pathol. 58:1134-1143.

Bertrand, P. F., and Brenneman, T. B. 2001. Aerial and weather based fungicide application for pecan scab control. Proc. Southeast Pecan Grow. Assoc. 94: 62-69.

Bock, C. H., Brenneman, T. B., Wood, B. W., and Stevenson, K. L. 2017. Challenges of managing disease in tall orchard trees-Pecan scab, a case study. CAB Rev. 12:1-18.

Bock, C. H., Cottrell, T. E., Hotchkiss, M. W., and Wood, B. W. 2013. Vertical distribution of scab in large pecan trees. Plant Dis. 97:626-634.

Brenneman, T., Bertrand, P., and Mullinix, B. 1998. Spray advisories for pecan scab: Recent developments in Georgia. Pages 7-13 in: Pecan Industry: Current Situation and Future Challenges, Third National Pecan Workshop Proceedings. USDA-ARS, Washington, DC.

Brent, K. J., and Hollomon, D. W. 2007. Fungicide Resistance in Crop Pathogens: How Can It Be Managed? FRAC Monograph No. 1 (2nd, rev. ed.). Fungicide Resistance Action Committee, Brussels, Belgium.

Brock, J., and Bertrand, P. 2007a. Pecan disease profile: Scab. Pages 185-187 in: Southeastern Pecan Growers' Handbook. L. Wells, ed. Univ. Georgia Coop. Ext. Bul. 1327.

Brock, J., and Bertrand, P. 2007b. Diseases of pecan in the southeast. Page 171 in: Southeastern Pecan Growers' Handbook. L. Wells, ed. Univ. Georgia Coop. Ext. Bul. 1327.

Bugbee, W. M. 1996. Cercospora beticola strains from sugar beet tolerant to triphenyltin hydroxide and resistant to thiophanate methyl. Plant Dis. 80:103.

Cancro, R. 2000. Sensitivity of Cladosporium caryigenum isolates to kresoximmethyl. M.Sc. thesis. University of Georgia, Athens, GA.

Cheeseman, J. M. 2006. Hydrogen peroxide concentrations in leaves under natural conditions. J. Exp. Bot. 57:2435-2444.

Chen, S. N., Luo, C. X., Hu, M. J., and Schnabel, G. 2016. Fitness and competitive ability of Botrytis cinerea isolates with resistance to multiple chemical classes of fungicides. Phytopathology 106:997-1005.

Cox, K. D., Bryson, P. K., and Schnabel, G. 2007. Instability of propiconazole resistance and fitness in Monilinia fructicola. Phytopathology 97:448-453.

Demaree, J. B. 1924. Pecan scab with special reference to sources of the early spring infections. J. Agric. Res. 28:321-333.

Fan, Z., Yang, J.-H., Fan, F., Luo, C.-X., and Schnabel, G. 2015. Fitness and competitive ability of Alternaria alternata field isolates with resistance to SDHI, QoI, and MBC fungicides. Plant Dis. 99:1744-1750.

Fungicide Resistance Action Committee (FRAC). 2013. Pathogen risk list. CropLife International, Brussels, Belgium. Retrieved from http://www.frac. info/publications/accept, August 2018.

Fungicide Resistance Action Committee (FRAC). 2018. FRAC code list. CropLife International, Brussels, Belgium. Retrieved from http://www.frac.info/ publications/downloads, August 2018.

Giannopolitis, C. N. 1978. Occurrence of strains of Cercospora beticola resistant to triphenyltin fungicides in Greece. Plant Dis. Rep. 62:205-208.

Giannopolitis, C. N., and Chrysayi-Tokousbalides, M. 1980. Biology of triphenyltin-resistant strains of Cercospora beticola from sugar beet. Plant Dis. 64:940-942.

Hawkins, N. J., and Fraaije, B. A. 2018. Fitness penalties in the evolution of fungicide resistance. Annu. Rev. Phytopathol. 56:339-360.
Hollomon, D. W. 2015. Fungicide resistance: Facing the challenge. Plant Prot. Sci. 51:170-176.

Ishii, H. 2015. Stability of resistance. Pages 35-48 in: Fungicide Resistance in Plant Pathogens. H. Ishii and D. W. Hollomon, eds. Springer Japan, Tokyo, Japan.

Karaoglanidis, G. S., and Thanassoulopoulos, C. C. 2002. Phenotypic instability of Cercospora beticola Sacc. strains expressing resistance to the sterol demethylation-inhibiting (DMI) fungicide flutriafol after cold exposure. J. Phytopathol. 150:692-696.

Karaoglanidis, G. S., Thanassoulopoulos, C. C., and Ioannidis, P. M. 2001. Fitness of Cercospora beticola field isolates - resistant and - sensitive to demethylation inhibitor fungicides. Eur. J. Plant Pathol. 107:337-347.

Köller, W., Smith, F. D., and Reynolds, K. L. 1991. Phenotypic instability of flusilazole sensitivity in Venturia inaequalis. Plant Pathol. 40:608-611.

Ma, Z., Proffer, T. J., Jacobs, J. L., and Sundin, G. W. 2006. Overexpression of the $14 \alpha$-demethylase target gene (CYP51) mediates fungicide resistance in Blumeriella jaapii. Appl. Environ. Microbiol. 72:2581-2585.

Mikaberidze, A., and McDonald, B. A. 2015. Fitness cost of resistance: Impact on management. Pages 77-89 in: Fungicide Resistance in Plant Pathogens. H. Ishii and D. W. Hollomon, eds. Springer Japan, Tokyo, Japan.

Møller, I. M., Jenson, P. E., and Hansson, A. 2007. Oxidative modifications to cellular components in plants. Annu. Rev. Plant Biol. 58:459-481.

Price, C. L., Parker, J. E., Warrilow, A. G. S., Kelly, D. E., and Kelly, S. L. 2015. Azole fungicides-Understanding resistance mechanisms in agricultural fungal pathogens. Pest Manag. Sci. 71:1054-1058.

Pringle, A., and Taylor, J. W. 2002. The fitness of filamentous fungi. Trends Microbiol. 10:474-481.

Reynolds, K. L., Brenneman, T. B., and Bertrand, P. F. 1997. Sensitivity of Cladosporium caryigenum to propiconazole and fenbuconazole. Plant Dis. 81:163-166.

Scheinpflug, H., and Kuck, K. H. 1987. Sterol biosynthesis inhibiting piperazine, pyridine, pyrimidine and azole fungicides. Pages 173-204 in: Modern Selective Fungicides-Properties, Applications and Mechanisms of Action. H. Lyr, ed. Wiley, New York, NY.

Schnabel, G., and Jones, A. L. 2001. The 14 $\alpha$-demethylase (CYP51A1) gene is overexpressed in Venturia inaequalis strains resistant to myclobutanil. Phytopathology 91:102-110.

Secor, G. A., Rivera, V. V., Khan, M. F. R., and Gudmestad, N. C. 2010. Monitoring fungicide sensitivity of Cercospora beticola of sugar beet for disease management decisions. Plant Dis. 94:1272-1282.

Seyran, M., Brenneman, T. B., and Stevenson, K. L. 2010. A rapid method to monitor fungicide sensitivity in the pecan scab pathogen, Fusicladium effusum. Crop Prot. 29:1257-1263.

Standish, J. R., Brenneman, T. B., and Stevenson, K. L. 2018. Dynamics of fungicide sensitivity in Venturia effusa and fungicide efficacy under field conditions. Plant Dis. 102:1606-1611.

Stevenson, K. L., Brenneman, T. B., and Brock, J. 2015. Results of the 2014 pecan scab fungicide sensitivity monitoring program. Ga. Pecan Grower's Mag. 26: 16-23.

Torres, M. A., Jones, J. D. G., and Dangl, J. L. 2006. Reactive oxygen species signaling in response to pathogens. Plant Physiol. 141:373-378.

Turechek, W. W., and Stevenson, K. L. 1998. Effects of host resistance, temperature, leaf wetness duration, and leaf age on infection and lesion development of pecan scab. Phytopathology 88:1294-1301.

Young, C. A., Bock, C. H., Charlton, N. D., Mattupalli, C., Krom, N., Bowen, J. K., Plummer, K. M., and Wood, B. W. 2018. Evidence for sexual reproduction: Identification, frequency and spatial distribution of Venturia effusa (pecan scab) mating type idomorphs. Phytopathology 108:837-846.

Ziogas, B. N., and Malandrakis, A. A. 2015. Sterol biosynthesis inhibitors: C14 demethylation (DMIs). Pages 199-216 in: Fungicide Resistance in Plant Pathogens. H. Ishii and D. W. Hollomon, eds. Springer Japan, Tokyo, Japan. 